\title{
EELS Study of the Electronic Structure Changes Associated with the Martensitic Transformation in a Cu-Al-Be Alloy
}

\author{
D. Ríos-Jara*, H. Flores-Zúñiga, M.T. Ochoa, F. Espinosa-Magaña \\ Centro de Investigación en Materiales Avanzados S.C. \\ Miguel de Cervantes \#120, 31109, Chihuahua, Chihuahua, México
}

Martensitic transformation has been observed in several materials and alloys. From these, Cu-based alloys have received considerable attention, because of their shape memory properties $[1,2]$. These alloys are characterized by a high temperature stable $\beta$-phase with cubic $\mathrm{DO}_{3}$-structure. This phase can be retained at room temperature by quenching it to a metastable phase which transforms, after cooling, to the martensitic $\beta$ '-phase with an orthorhombic 18R-type structure [3].

In this work, Electron Energy Loss Spectroscopy (EELS) in transmission mode was applied to a single crystal of $\mathrm{Cu}-11.24 \mathrm{wt} . \% \mathrm{Al}-0.5 \mathrm{wt} . \% \mathrm{Be}$ alloy, oriented in the [001] direction, in both low energy loss $(<50 \mathrm{eV})$ and high energy loss $(>50 \mathrm{eV})$ regions, in an in-situ heating-cooling cycle at $20,200,300,500,300,200$ and $20^{\circ} \mathrm{C}$ temperatures. Spectra were acquired with a Gatan PEELS (Model 766) attached to a Philips CM-200 TEM in diffraction mode.

Figures 1(a) and 1(b) show micrographs and diffraction patterns of the alloy at the beginning and the end of the thermal cycle, where it is clearly observed that a martensitic transformation has occurred.

The appearance of white lines at the threshold of $\mathrm{Cu} \mathrm{L}_{2,3}$ ionization edges in the alloys are taken as evidence that some electrons have left $3 \mathrm{~d} \mathrm{Cu}$ states after alloying. Furthermore, the enhancement of these white lines during the transition from austenite to martensite are related to a further increase of unoccupied states during the phase transformation. Figures 2(a) and 2(b) show EELS spectra for austenite and pure $\mathrm{Cu}$ and martensite and pure $\mathrm{Cu}$, respectively. Following the work by Pearson et al. [4], it is concluded that about 0.1 electrons/atom have left $\mathrm{Cu} 3 \mathrm{~d}$ states in austenite and 0.18 electrons/atom in martensite, that is, about 0.08 electrons/atom left $\mathrm{Cu} 3 \mathrm{~d}$ states during the phase transformation from austenite to martensite, probably to hybridized states in the alloy.

From the low energy loss region the Optical Joint Density of States (OJDS) were calculated. Differences in spectra for austenite and martensite are used to infer changes in the electronic band structure.

\section{References}

[1] International Conference on Martensitic Transformations (ICOMAT-95), Journal de Physique IV, 5, Colloque C8 (1995)

[2] International Conference on Martensitic Transformations (ICOMAT-98). Materials Science and Engineering A. Special Issue (1999)

[3] H. Warlimont, L. Delaey, Progress in Mat. Scien., 18 (1974) 25

[4] D.H. Pearson, C.C. Ahn and B. Fultz, Phys. Rev. B 47 (1993) 8471 
(a)

(b)
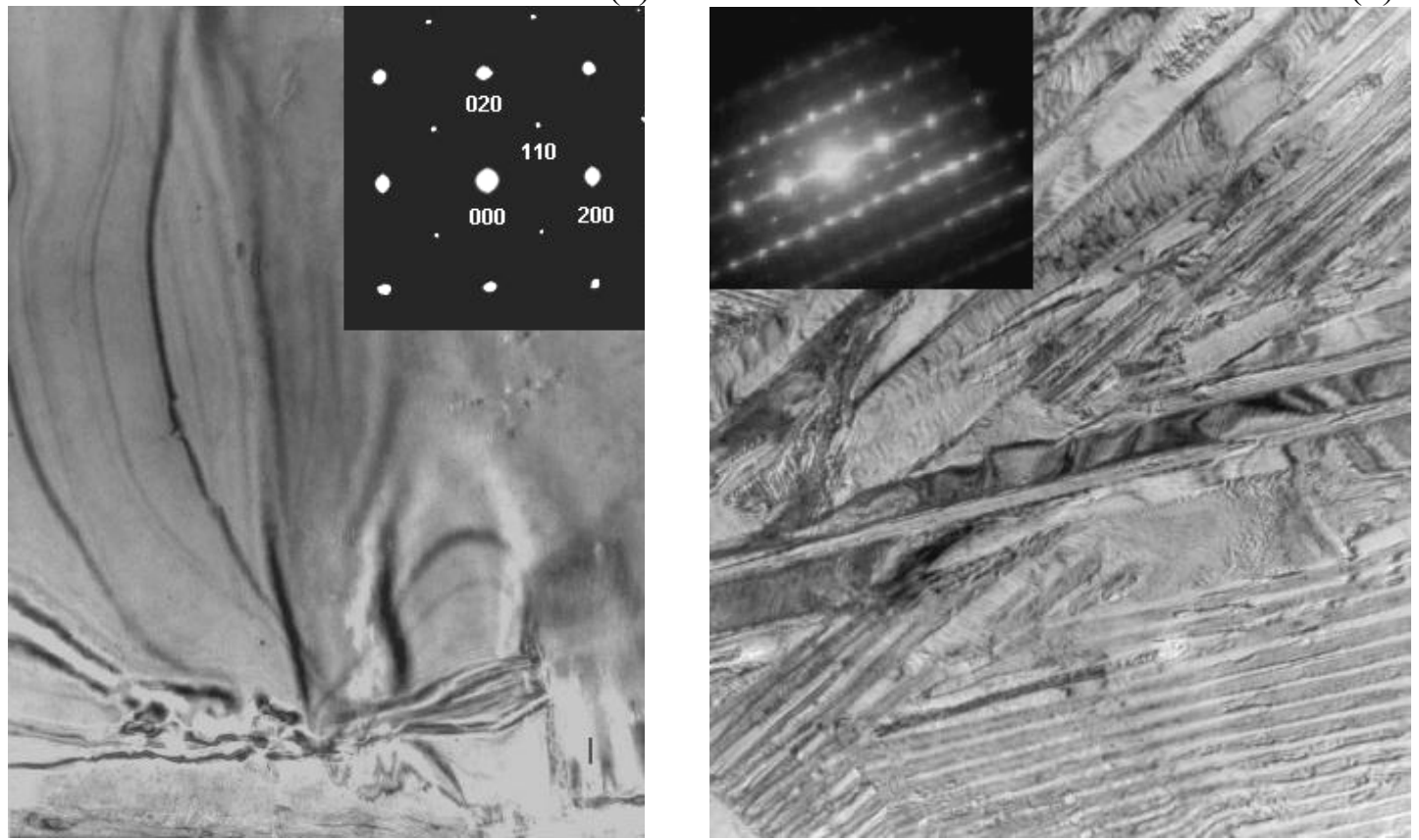

FIGS. 1a. and 1b. Micrographs and diffraction patterns from Austenite and Martensite.

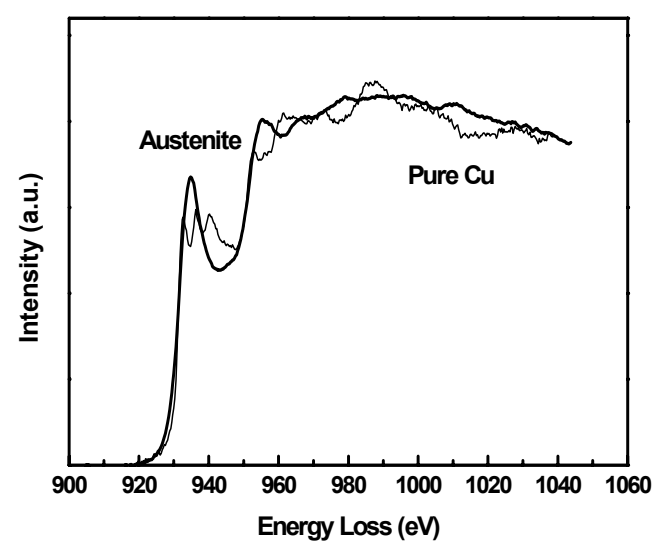

FIG. 2a. $\mathrm{Cu} \mathrm{L}_{2,3}$ ionization edges from Austenite and pure at room temperature

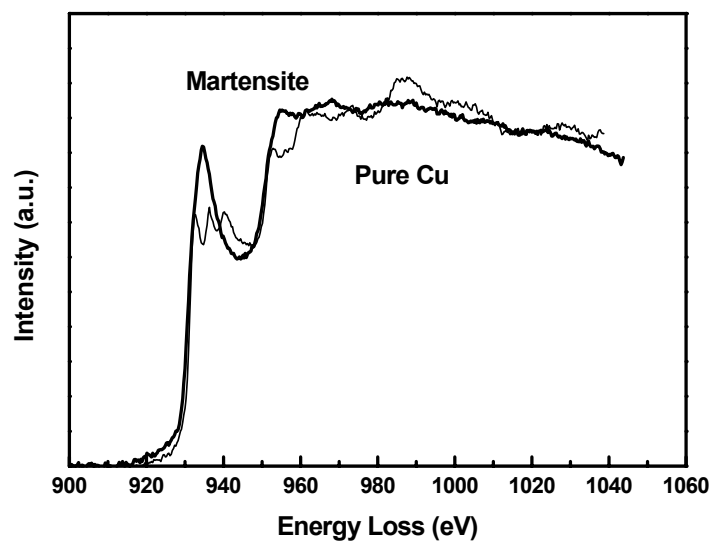

FIG. 2b. $\mathrm{Cu} \mathrm{L} \mathrm{L}_{2,3}$ ionization edges from Martensite at room temperature

*email: david.rios@cimav.edu.mx 